\title{
Divergência genética entre cultivares de gérbera utilizando marcadores RAPD
}

\author{
Genetic divergence among cultivars of gerbera using RAPD markers
}

\author{
Rodrigo Kelson Silva Rezende ${ }^{I^{*}}$ Luciano Vilela Paiva ${ }^{\text {II }}$ Renato Paiva ${ }^{\text {II }}$ \\ Antonio Chalfun Junior ${ }^{\mathrm{II}}$ Paula Pereira Torga ${ }^{\mathrm{II}}$ Tathiana Elisa Masetto ${ }^{\mathrm{I}}$
}

RESUMO

No processo de produção comercial de mudas de gérbera, a cor da flor é uma das principais características morfológicas de interesse agronômico, sendo uma característica importante em programas de melhoramento genético. A utilização de marcadores moleculares pode servir para direcionar cruzamentos, confirmar novos híbridos ou genótipos mutantes e identificar novos genótipos para fins comerciais. Nesse contexto, o objetivo deste trabalho foi analisar a divergência genética entre seis cultivares de Gerbera jamesonii ('Jaguar Yellow', 'Jaguar Cream', 'Jaguar Lemon', 'Jaguar Salmon Pastel', 'Jaguar Red', 'Jaguar Deep Rose'). A análise de divergência genética entre as cultivares de gérbera foi realizada utilizando-se 21 primers, os quais amplificaram 37 fragmentos polimórficos de DNA, que foram usados para estimar o coeficiente de Jaccard, o qual apresentou uma média de 0,38, variando de 0,28 a 0,56. A estrutura genética entre as cultivares foi estimada pelo UPGMA, revelando dois grupos distintos, a 38\% de similaridade genética. A maior similaridade genética encontrada (56\%) foi entre as cultivares 'Jaguar Yellow'e 'Jaguar Lemon'. Os resultados demonstram que a técnica RAPD oferece uma maneira rápida, relativamente barata e útil para a caracterização da divergência genética entre as diferentes cultivares de Gerbera jamesonii com relação à cor da flor.

Palavras-chave: Gerbera jamesonii, marcadores moleculares, Random Amplified Polymorphic DNA.

\section{ABSTRACT}

During the commercial production of gerbera seedlings, flower color is one of the main morphological aspects that have an agronomic interest and becoming an important feature in genetic breeding programs. The use of molecular markers may serve to direct crossings, new hybrids and mutants, besides confirm and identify new genotypes for commercial purposes. In that context, this work aimed to analyze the genetic divergence among six cultivars of Gerbera jamesonii ('Jaguar Yellow', 'Jaguar Cream', 'Jaguar Lemon', 'Jaguar Salmon Pastel', 'Jaguar Red', 'Jaguar Deep Rose'). The genetic divergence among cultivars of gerbera was carried out with 21 primers, which amplified 37 DNA polymorphic fragments, used to estimate the Jaccard index and presented an average of 0,38 , ranging from 0,28 to 0,56 . The genetic structure among cultivars was estimated by UPGMA and revealed two distinct groups, at 38\% genetic similarity. The largest genetic similarity found (56\%) was between cultivars 'Jaguar Yellow' and 'Jaguar Lemon'. The results showed that the RAPD is a fast, relatively inexpensive and useful technique for genetic divergence characterization between different cultivars of Gerbera jamesonii.

Key words: Gerbera jamesonii, molecular markers, Random Amplified Polymorphic DNA.

\section{INTRODUÇÃO}

As gérberas (Gerbera jamesonii) são plantas ornamentais provenientes da família das Asteráceas, originárias do sul da África (GERSTENBERGER \& SIGMUND, 1980).

Suas flores apresentam boa durabilidade e uma ampla variedade de cores, sendo a cor da flor uma das principais características morfológicas de interesse agronômico, além de uma característica importante em programas de melhoramento genético (REZENDE, 2005).

O uso de métodos altamente discriminatórios para a identificação e caracterização

IFaculdade de Ciências Agrárias, Universidade Federal da Grande Dourados (UFGD), CP 533, 79804-970, Dourados, MS, Brasil.

E-mail: rkelson@ufgd.edu.br.*Autor para correspondência.

IIUniversidade Federal de Lavras (UFLA), Lavras, MG, Brasil. 
de genótipos é essencial para programas de melhoramento e para a proteção de cultivares. Nos últimos anos, a utilização de marcadores moleculares tem possibilitado a realização de vários experimentos envolvendo o polimorfismo do DNA para o mapeamento genético, melhoramento de plantas assistido por marcadores, fingerprinting de genomas e para a investigação de parentesco genético em espécies ornamentais (DE BENEDETTI et al., 2001).

Marcadores moleculares, como o RAPD (Random Amplified Polymorphic DNA), são ferramentas que facilitam o estudo de diversas áreas da biologia, pura ou aplicada, como, por exemplo, na identificação de cultivares, evolução e genética de populações e nas análises de características quantitativas em genética de populações (SYMONDSON \& LIDDELL, 1996).

Em plantas ornamentais, já foram utilizados marcadores RAPD para o estudo da variabilidade genética de diversas espécies, como, por exemplo: Alstroemeria (ANASTASSOPOULOS \& KEIL, 1996), crisântemo (WOLFF \& PETERS-VAN RIJN, 1993), rosa (TORRES et al., 1993), lírio(YAMAGISHI, 1995), gérbera (DA MATTA et al., 2009), entre outras.

Dessa forma, a utilização de marcadores moleculares pode contribuir para o estudo de divergência genética entre diferentes cultivares de gérbera, com base na cor da flor como característica morfológica. Os marcadores moleculares podem servir para direcionar cruzamentos, confirmar novos híbridos ou genótipos mutantes e identificar novos genótipos para fins comerciais. (BERNET et al., 2003; BOLARIC et al., 2005).

A divergência genética tem sido avaliada com o objetivo de identificar combinações híbridas de maior efeito heterótico e maior heterozigose, de tal forma que, em suas gerações segregantes, tenha-se maior possibilidade de recuperação de genótipos superiores (REZENDE, 2005).

O objetivo deste trabalho foi analisar a divergência genética entre seis cultivares de Gerbera jamesonii por meio de marcadores RAPD.

\section{MATERIAL E MÉTODOS}

Plantas matrizes de seis cultivares de Gerbera jamesonii ('Jaguar Yellow', 'Jaguar Cream', 'Jaguar Lemon', 'Jaguar Salmon Pastel’, ‘Jaguar Red’, 'Jaguar Deep Rose’) foram cedidas pela empresa Multiflores, localizada em Lavras, MG. Procurou-se separar as cultivares de acordo com as cores das flores para identificação das mais divergentes, que poderão ser cruzadas e utilizadas em programas de melhoramento genético. Utilizou-se uma planta por cultivar, oriunda do plantio comercial através de semente (planta alógama). O DNA dos genótipos foi extraído a partir de folhas jovens por meio do método CTAB (brometo de cetiltrimetilamônio), descrito por MURRAY \& THOMPSON (1980) e ROGERS \& BENDICH(1985).

As reações de amplificação foram realizadas em termociclador modelo Mastercycler (Eppendorf, Hamburg, Germany), utilizando-se um programa com desnaturação inicial a $95^{\circ} \mathrm{C}$, por dois minutos, seguido por desnaturação a $94^{\circ} \mathrm{C}$, por um minuto, anelamento a $36^{\circ} \mathrm{C}$, por um minuto, e extensão a $72^{\circ} \mathrm{C}$, por dois minutos. Os passos de desnaturação, anelamento e extensão foram repetidos 34 vezes e, em seguida, a reação foi finalizada por uma extensão a $72^{\circ} \mathrm{C}$ por sete minutos. O volume final de cada reação de amplificação foi de $10 \mu \mathrm{L}$, contendo 50ng de DNA, 20mM Tris-HCl $\mathrm{pH} 8,4,50 \mathrm{mM} \mathrm{KCl}, 1,5 \mathrm{mM} \mathrm{MgCl}, 200 \mu \mathrm{M}$ de cada um dos desoxirribonucletídeos (dNTPs), 0,50 $\mu \mathrm{M}$ de primer e 0,5 unidades (U) da enzima Taq DNA polimerase (Invitrogen ${ }^{\circledR}$ ). Os fragmentos amplificados foram separados em gel de agarose $1 \%(\mathrm{~m} / \mathrm{v})$, com eletroforese a 70V em tampão TAE $1 \mathrm{X}(0,001 \mathrm{M}$ de EDTA pH 8,0; 0,04M de TRIS pH 8,0; 0,02M de ácido acético) por duas horas. Após a eletroforese, o gel foi incubado em solução de brometo de etídio $\left(0,5 \mu \mathrm{g} \mathrm{mL}^{-1}\right)$ por vinte minutos, lavado por dez minutos em água corrente, sendo visualizado sob luz ultavioleta e fotografado no equipamento EDAS $290\left(\operatorname{Kodak}^{\circledR}\right)$.

Foram utilizados os seguintes primers da série Operon (Operon Biotechnologies ${ }^{\circledR}$ ): OPA-01, OPA-02, OPA-03, OPA-04, OPA-05, OPA-07, OPA-08, OPA-09, OPA-12, OPA-14, OPA-15, OPA-16, OPA-17, OPA-18, OPA-19, OPA-20, OPB-01, OPB-02, OPB-04, OPB-06, OPB-07, OPB-08, OPB-10, OPC-04, OPC-06, OPC-07, OPC-08, OPC-09, OPG-02, OPG-03 e OPG-12.

A presença ou a ausência de bandas polimórficas foram marcadas por meio de interpretações visuais dos géis fotografados. Os dados foram transformados em matriz de 1 (presença) e 0 (ausência) de todos os genótipos e posições dos fragmentos.

Os valores de distância genética calculados, baseados no coeficiente de Jaccard, geraram uma matriz que foi utilizada para construção do dendrograma, que agrupou os genótipos segundo o método da média aritmética entre pares não ponderados (UPGMA, do inglês Unweighted Pair Group Method with Arithmetic Average), desenvolvido por SOKAL \& MICHENER (1958). Os dados foram processados com auxílio do programa computacional NTSYS - PC 2.0 (ROHLF, 1992), 
Cada agrupamento do dendrograma foi avaliado pela análise de bootstrap, utilizando-se 10.000 amostragens pelo programa BOOD 3.2 (COELHO, 2000). Para verificar o número mínimo de marcadores polimórficos necessários para gerar uma matriz de distância genética, foi utilizada a metodologia descrita por EFRON (1981) e implementado pelo programa GQMol (CRUZ \& SCHUSTER, 2004).

A diversidade genética do loco ou PIC (Índice de Conteúdo Polimórfico) é uma estimativa utilizada para a avaliação do poder discriminatório de um loco. A maior informatividade de uma classe de marcadores define sua maior eficiência em detectar polimorfismos entre dois indivíduos (RAFALSKI et al., 1996). A informatividade do loco $p_{i}$ é a freqüência do alelo $\mathrm{p}$ no loco $\mathrm{p}_{\mathrm{i}}$, calculado pela equação: $\mathrm{PIC}=1-\sum_{\mathrm{i}}$ $\mathrm{p}_{\mathrm{i}}{ }^{2}$, e a informatividade do primer $\mathrm{p}_{\mathrm{ij}}$ é a freqüência do alelo p do loco i, no primer j, sendo calculada pela equação: PIC $_{\text {primer }}=1-\sum_{\mathrm{i}} \cdot \sum_{\mathrm{j}} \mathrm{p}_{\mathrm{ij}}{ }^{2}$.

\section{RESULTADOS E DISCUSSÃO}

De um total de 31 primers testados, 21 foram capazes de amplificar fragmentos bem definidos e apresentar um padrão de bandas polimórficas entre as cultivares analisadas. Os 21 primers selecionados geraram 62 bandas, das quais 37 foram polimórficas (60\%). A informatividade desses primers variou de 0,83 (OPA-20) a 0,28(OPA-02, OPA-15eOPC-09) (Tabela 1). Trabalhando com 24 cultivares de gérbera, KWON et al. (2001) conduziram um estudo para analisar características morfológicas, como cor da flor, tipo de flor, diâmetro floral e talo floral. Eles encontraram um total de 57 bandas polimórficas amplificadas por 36 primers via RAPD. No entanto, os autores não encontraram relações genéticas entre as características morfológicas estudadas, havendo uma relação muito inconsistente entre marcadores moleculares e características morfológicas. Segundo os autores, a primeira hipótese é que se torna praticamente impossível identificar genes específicos relacionados com características morfológicas, visto que as cultivares usadas neste estudo têm grande variabilidade genética. A outra possibilidade é que muitos genes localizados em diferentes cromossomos podem ser responsáveis por características morfológicas, tais como cor da flor e tipo de flor.

Foi verificado que pelo menos 35 genes são responsáveis pela cor da flor em petúnia (WIERING \& DE VLAMING, 1984). Talvez a coloração das flores em gérbera seja controlada por vários genes, como relatado para petúnia.

Tabela 1 - Primers RAPD, números de produtos amplificados, PIC (Índice de Conteúdo Polimórfico) e número de bandas polimórficas obtidas em seis cultivares de gérbera ('Jaguar Yellow', 'Jaguar Cream', 'Jaguar Lemon', 'Jaguar Salmon Pastel’, 'Jaguar Red’, 'Jaguar Deep Rose').

\begin{tabular}{|c|c|c|c|c|}
\hline Primer & Sequência (5’- 3’) & $\mathrm{N}^{\mathrm{o}}$ de produtos amplificados & PIC & № de bandas polimórficas \\
\hline OPA-01 & CAGGCCCTTC & 3 & 0,44 & 1 \\
\hline OPA-02 & TGCCGAGCTG & 3 & 0,28 & 1 \\
\hline OPA-04 & AATCGGGCTG & 3 & 0,68 & 2 \\
\hline OPA-05 & AGGGGTCTTG & 3 & 0,44 & 1 \\
\hline OPA-07 & GAAACGGGTG & 3 & 0,44 & 1 \\
\hline OPA-08 & TGGACCGGTG & 3 & 0,64 & 2 \\
\hline OPA-09 & GGGTAACGCC & 3 & 0,68 & 2 \\
\hline OPA-12 & TCGGCGATAG & 3 & 0,44 & 1 \\
\hline OPA-14 & TCTGTGCTGG & 3 & 0,67 & 3 \\
\hline OPA-15 & TTCCGAACCC & 3 & 0,28 & 1 \\
\hline OPA-16 & AGCCAGCGAA & 2 & 0,50 & 1 \\
\hline OPA-19 & CAAACGTCGG & 3 & 0,80 & 3 \\
\hline OPA-20 & GTTGCGATCC & 4 & 0,83 & 3 \\
\hline OPB-02 & TGATCCCTGG & 2 & 0,68 & 2 \\
\hline OPB-06 & TGCTCTGCCC & 3 & 0,69 & 2 \\
\hline OPB-08 & CTCCACACGG & 4 & 0,78 & 3 \\
\hline OPC-04 & CCGCATCTAC & 3 & 0,81 & 3 \\
\hline OPC-07 & GTCCCGACGA & 3 & 0,44 & 1 \\
\hline OPC-09 & CTCACCGTCC & 2 & 0,28 & 1 \\
\hline OPG-03 & AGCGTCCTCC & 4 & 0,64 & 2 \\
\hline OPG-12 & CAGCTCACGA & 2 & 0,44 & 1 \\
\hline
\end{tabular}


Em estudo com marcadores moleculares em gérbera, foi verificado que 3 dos 10 primers inicialmente testados não foram eficientes na geração de bandas polimórficas; os demais primers geraram 11 bandas polimórficas. Padrões específicos de amplificação foram obtidos para as cultivares 'Sangria' e 'Sorrento', diferindo somente em dois fragmentos. As cultivares 'Francesca' e 'Rosabella' não apresentaram diferenças. Posteriormente, testou-se 16 novos primers para essas cultivares, sendo que somente duas de 60 bandas encontradas na cultivar 'Rosabella' estavam ausentes na cultivar 'Francesca' (DE BENEDETTI et al. 2001).

As 37 bandas polimórficas foram consideradas suficientes para uma adequada avaliação da divergência, uma vez que, nas análises de número ótimo de marcadores realizadas, verificou-se que a correlação entre as matrizes de distância aproximou-se de 1 e a soma dos quadrados dos desvios foi reduzida para 0,10, a partir da utilização de 25 bandas polimórficas (Figura 1). Assim, o aumento do número de bandas não alterou significativamente a estimativa da distância genética entre os indivíduos estudados.

Uma matriz binária foi construída a partir da análise das 37 bandas polimórficas e foi utilizada para estimar a similaridade genética entre as cultivares de Gerbera jamesonii. O coeficiente de Jaccard apresentou uma média de 0,38, variando de 0,28 a 0,56.

$\mathrm{O}$ agrupamento hierárquico das seis cultivares de Gerbera jamesonii, com base na matriz das distâncias genéticas pelo método UPGMA, demonstrou que a maior similaridade genética encontrada foi entre as cultivares 'Jaguar Yellow' e 'Jaguar Lemon' (56\%).
Considerando-se a separação do agrupamento a $38 \%$ de similaridade genética, obtiveram-se dois grupos distintos. Os grupos I e II são formados por quatro e duas cultivares, respectivamente. A respeito do grupo I, percebe-se a formação de dois subgrupos. O subgrupo IA inclui as cultivares ‘Jaguar Yellow’ e ‘Jaguar Lemon’, enquanto o subgrupo IB é formado pelas cultivares 'Jaguar Cream’ e ‘Jaguar Deep Rose’. O grupo II é formado pelas cultivares ‘Jaguar Salmon Pastel’ e ‘Jaguar Red’ (Figura 2).

Em experimento com 24 cultivares de gérbera, foi encontrado um coeficiente de similaridade de $72 \%$, variando de 50 a $90 \%$, sendo $90 \%$ a maior similaridade genética encontrada para as cultivares 'Sardana' (flores vermelhas/brancas) e ‘Tamara' (flores laranjas). As 24 cultivares foram agrupadas em cinco grupos distintos (KWON et al., 2001).

No presente trabalho, primers informativos foram determinados, o que permitiu a discriminação dos genótipos analisados. Através das informações obtidas, pode-se utilizar cultivares mais divergentes, possíveis de serem cruzadas para obtenção de uma população segregante, objetivando futuros estudos de mapeamento genético.

\section{CONCLUSÃO}

As seis cultivares de Gerbera jamesonii estudadas apresentam divergência genética detectada pela técnica de RAPD.

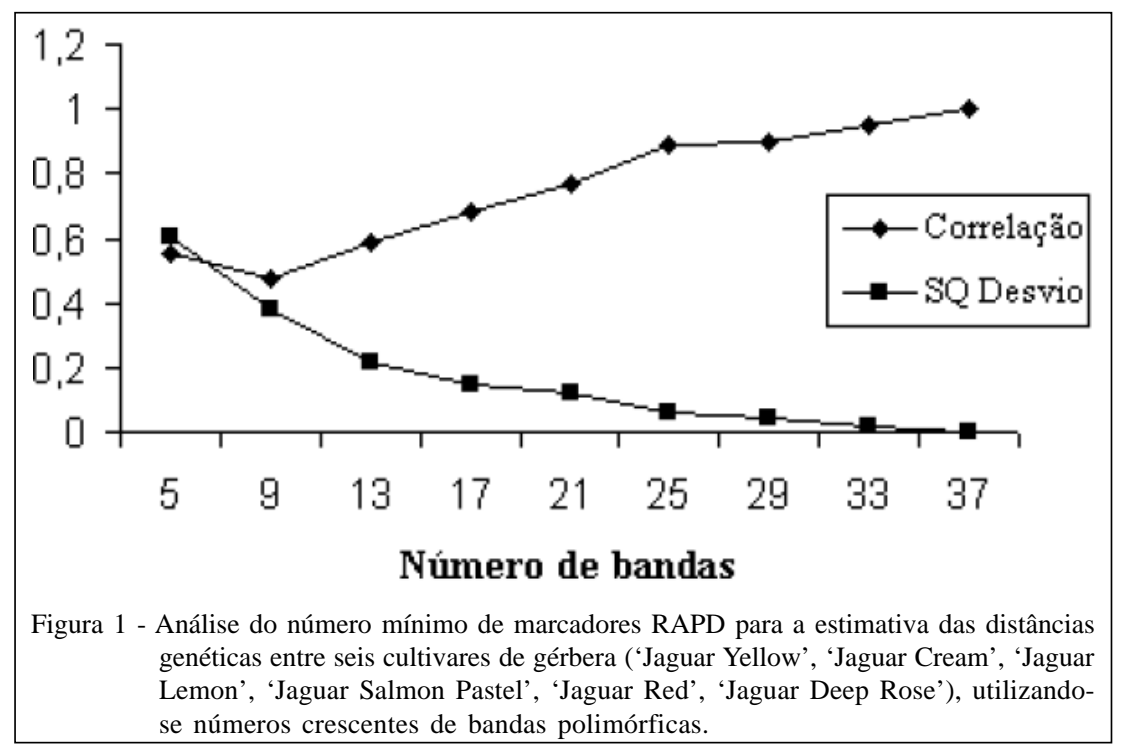

Ciência Rural, v.39, n.8, nov, 2009. 


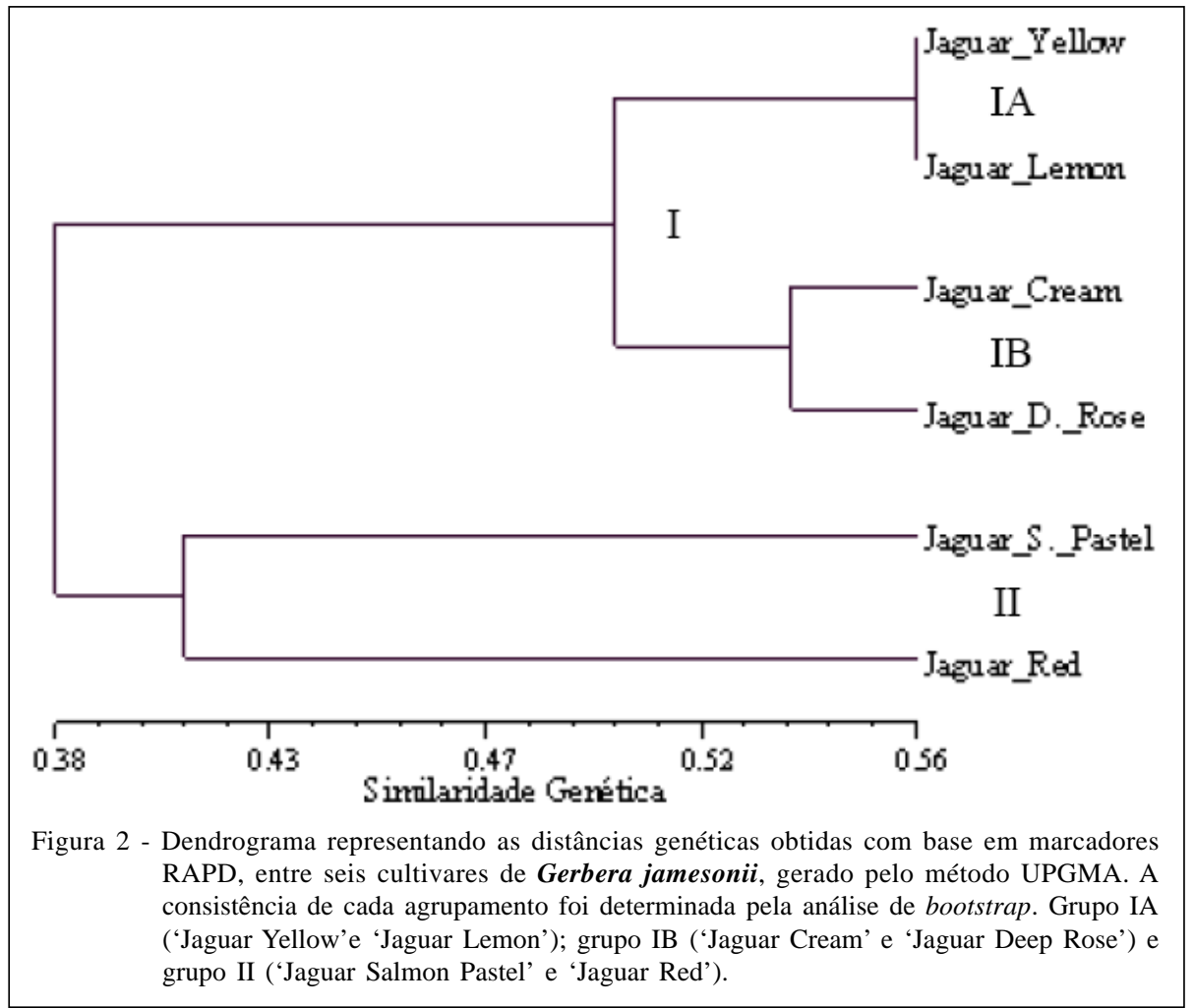

\section{REFERÊNCIAS}

ANASTASSOPOULOS, E.; KEIL, M. Assessment of natural and induced genetic variation in Alstroemeria using random amplified polymorphic DNA (RAPD) markers. Euphytica, v.90, p.235-244, 1996. Disponível em: <http://dx.doi.org/ 10.1007/BF00023864>. Acesso em: 20 jan. 2005. doi: 10.1016/S0022-474X(00)00016-3.

BERNET, G.P. et al. Applicability of molecular markers in the context of protection of new varieties of cucumber. Plant Breeding, v.122, p.146-152, 2003. Disponível em: <http:// dx.doi.org/10.1046/j.1439-0523.2003.00838.x>. Acesso em 17 jun. 2009. doi: 10.1046/j.1439-0523.2003.00838.x.

BOLARIC, S. et al. Molecular genetic diversity within and among German ecotypes in comparison to European perennial ryegrass cultivars. Plant Breeding, v.124, p.257-262, 2005. Disponível em: <http://dx.doi.org/10.1111/j.1439-0523.2005.01108.x>. Acesso em 17 jun. 2009. doi: 10.1111/j.14390523.2005.01108.x.

CRUZ, C.D.; SCHUSTER, I. GQMOL: aplicativo computacional para análise de dados moleculares e de suas associações com caracteres quantitativos. Versão 2.1. Viçosa: UFV, 2004. Disponível em: <http://www.ufv.br/dbg/gqmol/ gqmol.htm>. Acesso em: 13 jan. 2005.

DA MATA, T.L. et al. Genetic divergence among gerbera accessions evaluated by RAPD. Scientia Horticulturae, v.121, p.92-96, 2009. Disponível em: <http://dx.doi.org/ 10.1016/j.scienta.2009.01.026. Acesso em 17 jun. 2009. doi: 10.1016/j.scienta.2009.01.026.
DE BENEDETTI, L. et al. Genotype identification of ornamental species by RAPD analysis. Acta Horticulturae (ISHS), v.546, p.391-394, 2001.

EFRON, B. The bootstrap, the jackknife, and other resampling plants. Philadelphia: Society of Indian Applied Mathematics, 1981. 138p.

GERSTENBERGER, K.; SIGMUND, I. European horticultural statistics - Non - Edible products. HannoverGermany: Association Internationale des producteurs de L’Horticulture, Institut für Gartenbauökonomie University, 1980. p.173. (Institut für Gartenbauökonomie University, 28).

KWON, O. et al. Morphological characteristics and genetic variation of gerbera (Gerbera hybrida Hort). Journal of Plant Biotechnology, Daejon, v.3, n.3, p.145-149, 2001.

MURRAY, M.G.; THOMPSON, W.F. Rapid isolation of high molecular weight plant DNA. Nucleic Acids Reserch, v.8, p.1134-1137, 1980.

RAFALSKI, D.J.A. et al. Generating and using DNA markers in plant. In: BIRREN, B.; LAI, E. Non-mammalian genomic analysis: a practical guide. New York: Academic, 1996. p.75134.

REZENDE, R.K.S. Aspectos do cultivo in vitro e divergência genética em gérbera (Gerbera jamesonii). 2005. $91 \mathrm{f}$. Dissertação (Mestrado em Fisiologia Vegetal) - Universidade Federal de Lavras, Lavras, MG. 
ROGERS, S.O.; BENDICH, A.J. Extraction of DNA from milligram amounts of fresh, herbarium and mummified plants tissues. Plant Molecular Biology, v.5, p.69-76, 1985. Disponível em: <http://dx.doi.org/10.1007/BF00020088>. Acesso em 14 fev. 2005. doi: 10.1007/BF00020088.

ROHLF, F.J. Numerical taxonomy and multivariate analysis system: Version 1.70. New York: Exeter Software, 1992. 470p.

SOKAL, R.R.; MICHENER. C.D. A statistical methods for evaluating systematic relationships. [University Science Bulletin], Kansas, v.38, p.1409-1438, 1958.

SYMONDSON, W.O.C.; LIDDELL, J.E. The ecology of agricultural pests: biochemical approaches. London: Chapman \& Hall, 1996. 517p.

TORRES, A.M. et al. Identifying rose cultivars using Random Amplified Polymorphic DNA Markers. HortScience, n.28, p.333-334, 1993. Disponível em: <http://dx.doi.org/10.1016/ S0304-4238(96)00951-X>. Acesso em 19 fev. 2005. doi: 10.1016/S0304-4238(96)00951-X.

WIERING, H.; DE VLAMING, P. Genetics of flower and pollen colours. In: SINK, K. C. (Ed.). Petunia. Berlin: SpringerVerlag,1984. p.49-75.

WOLFF, K.; PETERS-VAN RIJN, J. Rapid detection of genetic variability in chrysanthemum (Dendranthema grandiflora Tzvelev) using random primers. Heredity, v.71, p.335-341, 1993. Disponível em: <http://dx.doi.org/10.1038/ hdy.1993.147>. Acesso em 10 jan. 2005. doi: 10.1038/ hdy.1993.147.

YAMAGISHI, M. Detection of section-specific random amplified polymorphic DNA (RAPD) markers in Lilium. Theoretical and Applied Genetics, v.91, p.830-835, 1995. Disponível em: <http://dx.doi.org/10.1007/BF00223888>. Acesso em 19 abr. 2005. doi: 10.1007/BF00223888. 